\section{Social-science programme hit by murder charge}

A civilian employee of the US Army's highly controversial 'Human Terrain' social-science programme has been charged with second-degree murder.

Although originally proposed as a means of improving relations between the military and locals in Afghanistan and Iraq, the Human Terrain programme has become mired in arguments about how much academics should be assisting military operations (see Nature 455, 583585 ; 2008).

According to an affidavit filed in a Virginia court, American Don Michael Ayala shot Afghani civilian Abdul Salam in the head while on patrol with the US Army in Afghanistan. At the time, Salam was restrained and handcuffed after attacking and badly injuring Paula Loyd, another member of the Human Terrain Team. Two Human Terrain researchers have died this year: Michael Bhatia in Afghanistan in May, and Nicole Suveges in Iraq in June.

\section{Distant world sports gassy signature of habitability}

Carbon dioxide has been spotted in the atmosphere of a gas-giant planet called HD 189733b, which orbits a star 63 light years from Earth.

Along with water and methane, which have already been detected in the atmospheres of other extrasolar planets, the presence of carbon dioxide could give astronomers clues about whether a planet might support life.

Mark Swain of NASA's Jet Propulsion Laboratory in Pasadena, California, reported his team's findings on 19 November at the Paris conference on Molecules in the Atmospheres of Extrasolar Planets.

The observations were made using the NICMOS near-infrared camera on the

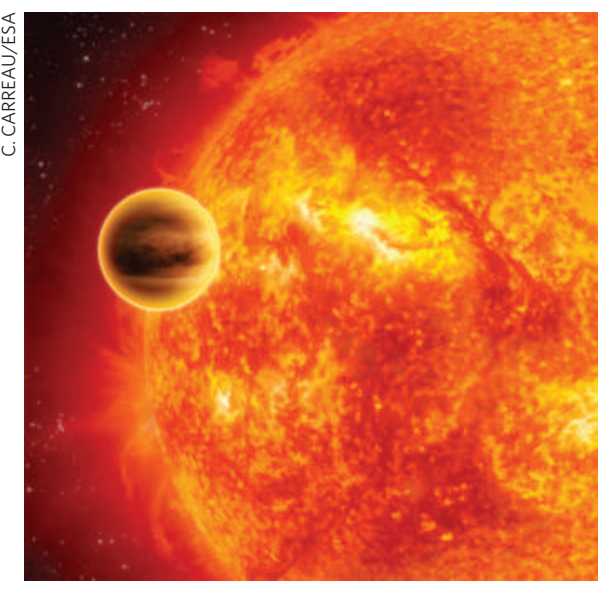

An artist's impression of planet HD 189733 b.

\title{
Deep-ocean observatories take the plunge
}

A deep-water ocean observatory

began operations off the west coast of North America earlier this month, making it the second to go live in the area this year.

On 10 November, the Monterey Bay Aquarium Research Institute in California began receiving data from its US\$13.5-million Monterey Accelerated Research System (part of it is pictured being lowered into the sea) - a platform the size of two small cars to which researchers can link their recording instruments to monitor earthquakes, sea acidification and animal life at a depth of 900 metres.

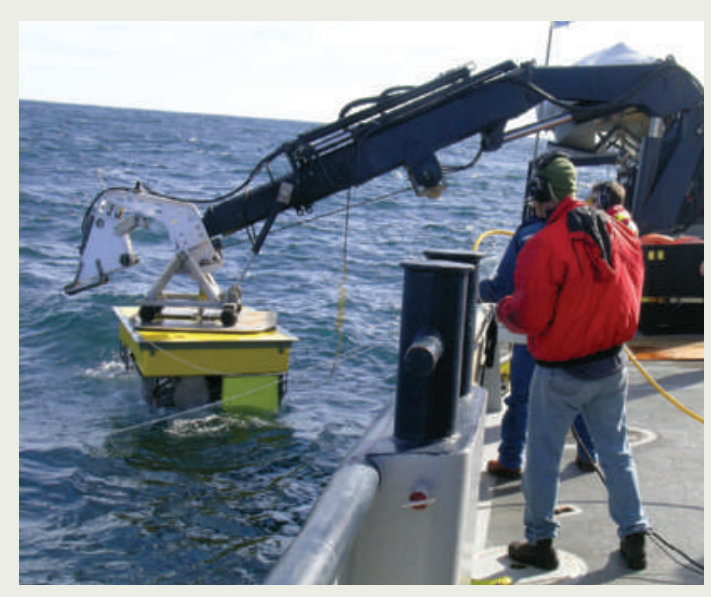

Meanwhile, Neptune Canada, which aims to be the world's largest cabled seafloor observatory, saw data from its first instrument node on 29 September. By the end of 2009 it should boast five nodes along an 800-kilometre cable loop, reaching depths of 2.7 kilometres to measure, for example, current speeds, water pressure and sonar signals.

Hubble Space Telescope. The detection of carbon dioxide is particularly surprising, because other forms of carbon, such as carbon monoxide and methane, would be expected to dominate the planet's hot, hydrogen-rich atmosphere.

\section{European Union declares Arctic interests}

The member states of the European Union (EU) have joined those countries staking an official interest in the Arctic, after the EU last week released a declaration of its "interests and policy objectives" in the far north. The European Commission billed it as the "first step towards an EU Arctic Policy".

The move comes amid steadily rising rhetoric from nations bordering the Arctic, with Russia, Canada and the United States rattling sabres over their rights to the area. As well as support for climatechange mitigation and oil exploration, the declaration also renews the EU's commitment to building a new research icebreaker, Aurora Borealis.

Further projects are promised that will monitor rising sea levels and the loss of sea ice and permafrost, as well as screening for organic chemicals and heavy metals in the region.

\section{United Kingdom auctions carbon emissions permits}

The United Kingdom raised nearly $€ 65$ million (US\$82 million) last week in the first auction of carbon-emission allowances in the second phase of the European trading scheme.
Industries that are part of the scheme need one carbon allowance for every tonne of carbon dioxide they emit into the atmosphere. These allowances have been distributed for free until now, but European Union (EU) rules allow governments to auction up to $10 \%$ of the permits between now and 2012, when phase two ends.

The country sold 4 million allowances at a rate of $€ 16.15$ per tonne on 19 November, marking a transition towards a system in which companies will be required to pay for the right to pollute. Other EU countries are preparing to follow suit, and the EU is debating rules that would require all carbon allowances to be auctioned from 2013.

\section{Unique collaborations at Howard Hughes institute}

The Howard Hughes Medical Institute (HHMI) in Chevy Chase, Maryland, has launched a pilot programme that will see HHMI money flowing directly to noninstitute scientists for the first time.

Through four-year Collaborative Innovation Awards, the HHMI will spend US\$40 million to fund eight teams of three to six scientists, headed by current HHMI investigators, which will tackle novel biological problems.

One of the projects aims to combat glaucoma, a leading cause of blindness, by developing a miniature, implantable wireless sensor that continuously monitors pressure within the eye. Another will try to identify a drug that can clear out the brain proteins thought to cause neurodegenerative disorders such as Alzheimer's disease. The institute expects to expand the programme in coming years. 